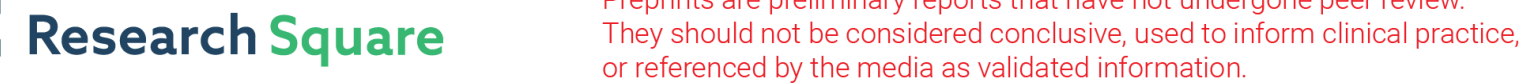

\section{Association of Chromosomal Aberrations and Maternal Serum Progesterone Levels in First Trimester Miscarriages: A Case Series}

\section{Paula Chiam}

Duke-National University of Singapore Medical School, 8 College Road, Singapore, 169857 Singapore

Cheryl Jia En Lim

Yong Loo Lin School of Medicine, National University of Singapore, NUHS Tower Block Level 11, 1E Kent Ridge Road, Singapore, 119228 Singapore

John C. Allen

Duke-National University of Singapore Medical School, 8 College Road, Singapore, 169857 Singapore

Kenneth Chang

Department of Pathology and Laboratory Medicine, KK Women's and Children's Hospital, Singapore, 100 Bukit Timah Road, Singapore, 229899 Singapore

\section{Min Hwee Yong}

Department of Pathology and Laboratory Medicine, KK Women's and Children's Hospital, Singapore, 100 Bukit Timah Road, Singapore, 229899 Singapore

\section{Nguan Soon Tan}

Lee Kong Chian School of Medicine, Nanyang Technological University Singapore, Clinical Sciences Building, 11 Mandalay Road, Singapore, 308232

Singapore

Thiam Chye Tan

Department of Obstetrics and Gynaecology, KK Women's and Children's Hospital, Singapore, 100 Bukit Timah Road, Singapore, 229899 Singapore Chee Wai Ku ( $\nabla$ cheewai.ku@mohh.com.sg)

Department of Obstetrics and Gynaecology, KK Women's and Children's Hospital, Singapore, 100 Bukit Timah Road, Singapore, 229899 Singapore

\section{Research Article}

Keywords: chromosomal aberrations, miscarriages, Serum, POC

Posted Date: April 26th, 2021

DOI: https://doi.org/10.21203/rs.3.rs-367747/v1

License: (9) (7) This work is licensed under a Creative Commons Attribution 4.0 International License. Read Full License 


\section{Abstract}

Fetal genetic aberrations constitute up to $50 \%$ of all early miscarriages, with aneuploidies accounting for the majority. Serum progesterone is useful in triaging women presenting with threatened miscarriage, and a low progesterone level has been associated with an increased risk of miscarriage. This study examined the association between chromosomal aberrations and maternal serum progesterone level measured at presentation with threatened miscarriage. In this prospective cohort study, we that recruited women who presented with threatened miscarriage and subsequently progressed to a complete miscarriage at or before 16 weeks of gestation. 9 patients with products of conception (POC) available were analysed. They were triaged at presentation based on their serum progesterone level and patients with a level $<35 \mathrm{nmol} / \mathrm{L}$ were treated with oral progestogen according to the hospital department protocol. Genetic material extracted from the POC was analysed with chromosomal microarray. In these 9 patients, most miscarriages (88\%) were due to fetal genetic abnormalities and the most common genetic anomalies was trisomy (57\%). Patients with abnormal POC karyotype had a low mean serum progesterone level of $24.0 \pm 23.3$ $\mathrm{nmol} / \mathrm{L}$. This level is much lower than the patient with a normal POC karyotype, who had a serum progesterone level of $42.9 \mathrm{nmol} / \mathrm{L}$. The most common cause for miscarriages in this study was genetic anomalies and these affected patients had a low serum progesterone level ( $<35 \mathrm{nmol} / \mathrm{L})$. These patients miscarried despite treatment with oral progestogen, due to underlying fetal genetic abnormalities. Further studies should be conducted to validate the association between serum progesterone and genetic abnormalities and shed light on the etiologies and improve risk stratification for threatened miscarriage.

\section{Introduction}

Fetal chromosomal abnormalities have been found to constitute up to $50 \%$ of first trimester miscarriages and up to a third of second trimester miscarriages without underlying medical conditions [1, 2]. Many cytogenetic studies have since investigated the types of abnormalities that led to these early miscarriages and numerical chromosome abnormalities (trisomies, monosomies and polyploidy) were found to be the most common [2]. Some studies have also explained that the majority of chromosomal abnormalities occurred de novo and were a result of random errors produced during gametogenesis and embryonic development [3]. The risk of fetal chromosomal aberrations was also noted to increase with advanced maternal age [4], which is especially relevant in our population, where the average age of women bearing their first child had increased over the years.

Nonetheless, the cause of miscarriage is often multifactorial, and many factors have been found to contribute to spontaneous miscarriage. The physiological importance of progesterone for the establishment and maintenance of a pregnancy has been well-documented, and luteal phase deficiency has been shown to contribute to up to $5-11 \%$ of early miscarriages. Numerous studies have shown that low progesterone level is associated with an increased risk of miscarriage $[5,6]$. Serum progesterone was used to triage women who presented with threatened miscarriage, with a validated cut-off of $35 \mathrm{nmol} / \mathrm{L}[7,8,9]$. Women with serum progesterone $<35 \mathrm{nmol} / \mathrm{L}$ were treated with oral progestogen, while those with serum progesterone $\geq 35 \mathrm{nmol} / \mathrm{L}$ were managed conservatively. While it can predict the risk of spontaneous miscarriage for these women, there is still a significant number of women who eventually miscarried despite oral progestogen treatment, and a small number miscarried despite having a progesterone level $\geq 35 \mathrm{nmol} / \mathrm{L}$. This highlights the multifactorial etiology of early miscarriages beyond luteal phase deficiency.

In this study, we aimed to determine the presence of genetic aberrations by analysing the products of conception (POC) of women who had an early spontaneous miscarriage before 16 weeks of gestation using cytogenetics techniques. These patients have been triaged at presentation based on their serum progesterone, and patients with low levels were treated with oral progestogen.

Establishing an association between chromosomal aberrations and miscarriages, and how this relates to maternal serum baseline (pre-treated) progesterone levels, would enrich our current understanding of miscarriage and enable us to better counsel women about the cause of their pregnancy loss. It is hoped that this would reduce the self-blame and anxiety experienced by women who ultimately miscarried despite treatment with oral progestogens, which would not have salvaged a karyotypic abnormality in the fetus.

\section{Methods}

\section{Study Recruitment}

The patients recruited were part of a prospective cohort study consisting of 157 patients, aged 21 years old and above, who presented to the Urgent Obstetrics and Gynaecology Centre (UOGC) at KK Women's and Children's Hospital (KKH), between January 2017 and January 2020, with a threatened miscarriage defined as vaginal bleeding with or without abdominal pain. Inclusion criteria were a single intrauterine pregnancy, between gestational week 6 and 10 (confirmed and dated by ultrasonography), with pregnancy-related per vagina bleeding. Women with previous episodes of per vagina bleeding in the current pregnancy, or women diagnosed with inevitable miscarriage, missed miscarriage, blighted ovum or planned termination of pregnancy were excluded. These patients were followed up till 16 weeks of pregnancy. Those who had a miscarriage at or before 16 weeks and with POC for analysis were then included in this study $(n=9)$. A flowchart of the study recruitment is summarised in Fig. 1.

After written informed consent was obtained, the patients were interviewed using an investigator-administered questionnaire in either English or Chinese language to collect data on demographic and obstetric variables (Table 1). After consent was obtained, the medical records of the women were also studied to supplement the data collected during the interview. This study was approved by the SingHealth Centralised Institutional Review Board (CIRB Ref 2016/2950 and 2019/2513). All research described in this manuscript was performed in accordance with relevant guidelines and regulations.

\section{Maternal Serum Progesterone Level at Presentation}

For all the participants, maternal blood samples were taken at the time of their initial presentation with threatened miscarriage to measure their serum progesterone level. The blood was collected in plain tubes and centrifuged for 10 minutes at $3000 \mathrm{~g}$ within 2 hours of collection. Serum progesterone level was 
measured in the KKH clinical laboratory using a commercial ARCHITECT progesterone kit (Abbott, Ireland). Women found to have low serum progesterone (defined as $<35 \mathrm{nmol} / \mathrm{L}$ ) were treated with oral progestogen, in keeping with the standard of care for women presenting with threatened miscarriage in $\mathrm{KKH}$. Women with serum progesterone $\geq 35 \mathrm{nmol} / \mathrm{L}$ were not given any progestogen supplementation according to the department protocol.

\section{Chromosomal Microarray-Based Analysis}

Chromosomal microarray analysis (CMA) was chosen over traditional karyotype techniques to detect genetic abnormalities in the POC in these patients because of the diagnostic superiority and sensitivity of CMA. The villous tissue from the participants' POC products was also obtained and formalin-fixed, paraffin-embedded before being analysed via the OncoScan ${ }^{\circledR}$ assay in KKH's cytogenetics lab as per manufacturer's protocol described. The OncoScan ${ }^{\circledR}$ assay (Thermo Fisher Scientific) utilizes Molecular Inversion Probe (MIP) technology, which allows for genomic analysis of formalin-fixed, paraffin-embedded (FFPE) samples with degraded DNA and low DNA yield. This technology contains more than 220,000 probes across the genome to detect DNA copy number (CN) gains, losses, and copy neutral absence of heterozygosity $(\mathrm{AOH})$.

Genomic DNA (gDNA) was extracted from FFPE villus tissue using ReliaPrep ${ }^{\circledR}$ gDNA FFPE kit (Promega, Madison, WI, USA) and quantified using Qubit Fluorometer (Promega) following the manufacturers' recommended protocol.

Normalization of QubitR-determined FFPE DNA Concentration was calculated to convert the Qubit-determined DNA concentration to PicoGreen equivalent value. PicoGreenR dsDNA quantification assay has been used primarily to determine the amount of assay input DNA during the development of OncoScan product. The DNA stock concentration was adjusted to $12 \mathrm{ng} / \mu \mathrm{l}$, by diluting with EDTA 1x TE buffer (10 mM Tris- $\mathrm{HCl}, 0.1 \mathrm{mM}$ disodium EDTA, pH 8 ) or by concentration by vacuum evaporation, depending on the starting concentration.

The Oncoscan microarray assay has been described at length by Jung, H., Lefferts, J.A. \& Tsongalis, G.J. Utilization of the Oncoscan microarray assay in cancer diagnostics. Appl Cancer Res 37, 1 (2017).

Briefly, the extracted gDNA and the MIP copy number probes were denatured at $95^{\circ} \mathrm{C}$ for 5 minutes and allowed to hybridise at $58^{\circ} \mathrm{C}$ overnight $(16-18$ hours). Each sample was then split into two and the annealed probes were gap filled by adding a mix of $d A T P(A)$ and dTTP(T) nucleotides in one reaction and a mix of $\operatorname{dGTP}(G)$ and dCTP(C) nucleotide to the other. Noncircular forms of the MIP probes, together with gDNA, were digested by a cocktail of exonucleases specific for linear DNA. Hence, only circular forms of MIP probes that have a gap filled by the A/T or G/C nucleotides were left behind. The circular MIP probes were then cut by a cleavage enzyme into linear forms and amplified by two rounds of PCR. The resulting amplicons were cleaved into two fragments with the Haell enzyme, of which the smaller (44bp) fragment, containing the unique tag sequence to the assigned gDNA, was hybridized onto the OncoScan $\AA$ assay arrays. The two reactions were individually hybridized into two separate (but same) microarray at $49^{\circ} \mathrm{C}$ overnight (16-18 hours). Following hybridization, the arrays were stained and washed using the GeneChip ${ }^{\circledR}$ Fluidics Station 450 (Thermo Fisher Scientific) and loaded into the GeneChip ${ }^{\circledR}$ Scanner GCS 3000 (Thermo Fisher Scientific) where array fluorescence intensity was scanned, and array images (DAT file) was generated. Subsequently, the DAT files were converted into Array fluorescence intensity (CEL) files by the Affymetrix ${ }^{\circledR}$ GeneChip ${ }^{\circledR}$ Command Console ${ }^{\circledR}$ (AGCC) Software version 4.0 and analysed using Chromosome Analysis Suite (ChAS) software version 3.2.0.1252

\section{Statistical Methods}

All the statistical analysis reported in this study was done using the SAS version 9.4 software, SAS Inc. Cary, NC USA. P-values were calculated using Fisher's exact test, with p-value of $<0.05$ considered statistically significant.

\section{Details of ethics approval}

This study was approved by the SingHealth Centralised Institutional Review Board (CIRB Ref 2016/2950 and 2019/2513).

\section{Results}

A total of 157 patients were recruited as part of a prospective cohort study, with 37 patients excluded or lost to follow-up. These patients were then triaged into having serum progesterone level $\geq 35 \mathrm{nmol} / \mathrm{L}(\mathrm{n}=104)$ and serum progesterone level $<35 \mathrm{nmol} / \mathrm{L}(\mathrm{n}=16)$. Of the patients who had serum progesterone $\geq 35$ $\mathrm{nmol} / \mathrm{L}, 11.5 \%(\mathrm{n}=12)$ miscarried at or before 16 weeks of gestation. 4 of these patients had POC for analysis. The POC karyotypes of these patients are as follows: 2 had abnormal POC karyotypes, 1 had a normal POC karyotype and 1 had a genetically indeterminate POC due to poor DNA quality. Amongst the patients with serum progesterone $<35 \mathrm{nmol} / \mathrm{L}, 93.8 \%(\mathrm{n}=15)$ miscarried at or before 16 weeks and 5 had POC for analysis - of which all were abnormal. The characteristics of the participants at baseline and the chromosomal microarray-based analysis results are summarised in Table 1.

\section{Maternal Characteristics}

The age of the patients ranged from 23 to 37 years with a mean of $32.7 \pm 4.2$ years. Patients who were found to have an abnormal POC karyotype had an older mean age of $34.1 \pm 4.2$ years. The mean BMl of the participants was $25.2 \pm 5.5 \mathrm{~kg} / \mathrm{m} 2$. The mean gestational age of the participants at the time of complete miscarriage was $7.62 \pm 1.48$ weeks. It is worth noting that participants with an aberrant chromosomal POC tended to experience an earlier miscarriage at a mean of $7.35 \pm 1.54$ weeks gestation. They were also noted to have a shorter interval between the gestational age at initial presentation and at complete miscarriage of $0.78 \pm 0.93$ weeks compared to the patient with normal POC karyotype (case 6 ) who had an interval of 2.59 weeks.

\section{Genetic Profiles of POC}

Of the nine POC analysed, seven (88\%) were positive for chromosomal aberration, one had a normal karyotype (case 6) and one had indeterminate results (case 8) due to the poor DNA quality in the sample. Of the seven POC with chromosomal aberration, the most frequent aberration was autosomal trisomy 
which was present in four POC (57\%), including one case of concomitant autosomal trisomy 22 with monosomy X. The trisomies detected in this study include: trisomy 5, 7, 8, 16, 20, 22. Following trisomies, the second most frequent aberration detected were mosaic genome-wide uniparental disomy (UPD) in cases 2 and 4, and Monosomy $\mathrm{X}$ in cases 7 and 9.

Furthermore, patients with abnormal POC karyotype were found to have a lower mean maternal serum progesterone level at $24.0 \pm 23.3 \mathrm{nmol} / \mathrm{L}$, compared to the only participant with a normal karyotype POC who had a normal progesterone level of $42.9 \mathrm{nmol} / \mathrm{L}$. It was also noted that cases 7 and 9 had an abnormal POC karyotype despite a normal progesterone level.

\section{Discussion}

\section{Main findings}

Amongst the women who presented with threatened miscarriage and had POC available for analysis $(n=9)$, seven out of eight $(88 \%)$ were found to have chromosomal aberrations in their POC. This percentage is consistent with studies showing that the presence of a major fetal chromosomal abnormality accounts for as many as $50 \%$ of all first-trimester pregnancy losses $[1,2,10]$. These women with an abnormal Poc karyotype also had a lower mean serum progesterone level at $24.0 \pm 23.3 \mathrm{nmol} / \mathrm{L}$. This is consistent with studies that found progesterone levels to be lower in pregnancies with chromosomal abnormalities, particularly trisomies 16, 18, 21 and $22[11,12]$. Progesterone plays an important role in maintaining the pregnancy and preventing miscarriage by preparing the uterus for implantation. It maintains decidualization of the endometrium to facilitate implantation [13]. Despite this, patients who were given progestogen supplementation (cases 1 to 5 ) still eventually miscarried, and chromosomal aberrations were found in all five POC. These results might lend a new perspective to the findings of the recently published randomized controlled trials of progestogens for the treatment of miscarriages. The Progesterone in Spontaneous Miscarriage (PRISM) trial showed that women with threatened miscarriage and subsequently randomized to receive vaginal progesterone or placebo, did not result in a higher incidence of live births in the treatment arm [14]. A recent randomised, double-blind controlled study conducted in Asia also concluded that oral progestogen given to women with first trimester threatened miscarriage did not reduce the risk of miscarriage or improve the eventual live birth rate [15]. The study found that oral progestogen treatment did not significantly reduce the rate of miscarriage between the placebo and treatment groups, which had a high pre-treatment progesterone level of 69 and $67 \mathrm{nmol} / \mathrm{L}$ respectively. The findings from our study could potentially account for the lack of response to progestogen treatment, especially when the underlying etiology for miscarriage is due to chromosomal aberrations. This suggests that progestogen supplementation is likely useful only in the context of low serum progesterone, particularly in the context of luteal phase deficiency. Low serum progesterone level had been associated with an increased risk of miscarriage [16]. Targeted treatment for this group of patients could potentially reduce the risk of miscarriage and increase live birth rates. This paves the way for future randomised controlled trials for women with low serum progesterone, who would most likely benefit from progestogen supplementation.

Of the seven POC with chromosomal aberrations, the most frequent was autosomal trisomy present in four (57\%) POC; namely Case 1, 3, 5, and 7, which had a concomitant autosomal trisomy 22 with monosomy $X$. This result is consistent with numerous early miscarriages chromosomal studies, which similarly found that trisomy - whether for a single chromosome or multiple chromosomes (multiple trisomy), was the most common abnormality detected in POC of pregnancy loss [17]. It has been speculated that variations in nondisjunction and differential selection may be responsible [4]. Following trisomies, the second most frequent aberration detected were mosaic genome-wide UPD in all autosomes (case 2 and case 4) and Monosomy X (case 7 and case 9 ), each making up $29 \%$ of the genetically aberrant POC. The relatively high frequency of mosaic genome-wide UPD is surprising given that mosaic abnormalities do not typically constitute a high frequency of all chromosomal aberrations detected, in which mosaic abnormalities were found in $4.9 \%$ of all cases of chromosomal aberrations [18]. The genome-wide uniparental diploidies result primarily from a functional imbalance of virtually all parentally imprinted loci [19]. Monosomy $\mathrm{X}$ was found to constitute around $10 \%$ of chromosomal abnormalities detected in other POC studies in women who had an early spontaneous miscarriage, and it is the third most common abnormality after autosomal trisomy and polyploidy [20,21, 22]. It is hypothesized that anaphase lag or other mitotic events are responsible for the loss of a sex chromosome in conceptions that started as diploid XX or XY [23]. The high incidence of genome-wide UPD mosaic and monosomy $X$ in our study is likely to be contributed by the limited sample size.

Maternal age is a known risk factor for chromosomal aberrations and spontaneous miscarriages. An increase in chromosomal anomaly rate was found in women 35 years and older when compared with younger women [24]. Indeed, the mean maternal age of the patients who miscarried was older (32.7 \pm 4.2 years). Regarding gestational age, patients with chromosomal aberrant POC took a shorter time of $0.74 \pm 0.93$ weeks to progress from threatened miscarriage to complete miscarriage as compared to case 7, which had a normal POC karyotype and progressed from threatened to complete miscarriage in 2.59 weeks. This could be explained by the strong correlation between chromosomal abnormality and severely disorganized fetal development resulting in developmental arrest and eventual abortion [1].

A normal karyotype and serum progesterone do not always result in a normal pregnancy (case 6). The etiology of an euploid miscarriage is likely multifactorial, with maternal causes, such as uterine structural anomalies, antiphospholipid syndrome, hereditary thrombophilia, other endocrine abnormalities and immune factors [20] or fetal causes, such as structural abnormalities, being commonly cited.

\section{Implication for Clinical Practice}

Serum progesterone is a good biomarker to triage women presenting with threatened miscarriage into a high or low risk group, thus guiding the treatment of high-risk patients with progestogens supplementation [16]. However, the success of the treatment will likely depend on the underlying etiology, which is not evident based on serum progesterone alone. Chromosomal aberrations are common in women who miscarried, and our study contributes to the existing literature in guiding the counselling for these women. This is especially important because knowing the possible irreversible etiologies of miscarriage can 
result in better closure and reduce the feelings of self-blame. This would provide these affected women with reassurance and confidence as she prepares for her subsequent pregnancy [25].

There is limited data on the risk of miscarriage in subsequent pregnancies, after a previous spontaneous miscarriage. Early spontaneous miscarriages are thought to occur on a random basis and most patients are likely to have a successful pregnancy after a first miscarriage [26-28]. Although some studies that suggested a risk of recurrence of both autosomal and sex chromosome fetal aneuploidy in women with a previous spontaneous miscarriage of aneuploid conceptions [29-32], there is insufficient evidence to routinely screen all patients after one miscarriage. However, POC analysis may be done for patients who experience three or more miscarriages, with subsequent parental karyotype being tested if inheritable genetic aberrations are found, such as balanced translocations $[33,34]$

\section{Strength and Limitation}

This is the only study, to our knowledge, that correlates genetic profile with the outcome of pregnancy in a cohort of women with serum progesterone performed at presentation with threatened miscarriage. A limitation of this study is its relatively small sample size due to the difficulty of obtaining adequate POC for cytogenetic analysis. Nonetheless, it is hoped that this study can provide the impetus for future larger scale studies proving a clinically important relationship between maternal baseline progesterone status and the presence of chromosomal aberrations.

\section{Conclusion}

This study demonstrated that genetic aberrations and low serum progesterone levels were a common cause of spontaneous miscarriage. Progestogen treatment is unlikely to prevent a miscarriage secondary to genetic abnormalities. This may provide the basis for equivocal results for progestogen treatment amongst women with threatened miscarriage and highlights the need for a randomized controlled trial in women with low serum progesterone where the incidence of luteal phase deficiency treatment effect is likely the highest. Most importantly, our study provides the basis for anticipatory guidance and counselling for women after a spontaneous miscarriage, about possible irreversible etiologies such as chromosomal abnormalities, thus relieving potential anxiety and self-guilt.

\section{Declarations}

\section{Acknowledgements}

The authors would like to thank the Department of Pathology for their support -Mr Kuick Chik Hong and Ms Tan Mui Li and our clinical research coordinators

- Ms Doris Ong, Ms Carol Seah, Ms Trish Koon and our patients.

\section{Authors' contribution}

P.C. contributed to the development of the research design, analysis strategy, conducted patient recruitment and follow-up and is the co-first author of the manuscript. C.J.E.L. contributed to the data interpretation, manuscript writing, revision, and editorial support, and is the co-first author of the manuscript. J.C.A. performed the statistical analyses, contributed to the interpretation of results and presentation, and provided editorial guidance. K.C. performed the analysis and interpretation of the POC data for the study. M.H.Y. performed the analysis and interpretation of the POC data for the study. N.S.T. contributed to experimental design, interpretation of results and presentation, and provided editorial guidance. T.C.T. contributed to the development of research design, analysis strategy, provided editorial support. C.W.K. contributed to the research design, analysis strategy, conducted patient recruitment, provided editorial support, and is the principal investigator of the SingHealth Duke-NUS Obstetrics \& Gynaecology Academic Clinical Programme Research Support Programme Grant, Nurturing Clinician Scientist Scheme. All authors have reviewed and approved the final version of the paper.

\section{Funding}

This study is funded by the SingHealth Duke-NUS Obstetrics \& Gynaecology Academic Clinical Programme Research Support Programme Grant, Nurturing Clinician Scientist Scheme (NCSS)-01/FY2019/P1/14-A29.

\section{Competing interests}

The authors declare no competing interests.

\section{Additional Information}

Correspondence and requestions for materials should be addressed to C.W.K.

\section{References}

1. Hardy, K. \& Hardy, P. J. 1st trimester miscarriage: four decades of study. Translational pediatrics. 4 (2), 189-200 https://doi.org/10.3978/j.issn.22244336.2015.03.05 (2015).

2. Goddijn, M. \& Leschot, N. J. Genetic aspects of miscarriage. Bailliere's Best Pract. Res. Clin. Obstet. Gynaecol. 14 (5), $855-865$ https://doi.org/10.1053/beog.2000.0124 (2000).

3. Rubio, C. et al. Embryo aneuploidy screening for unexplained recurrent miscarriage: a minireview. Am. J. Reprod. Immunol. 53 (4), 159-165 (2005). 
4. Hassold, T. \& Chiu, D. Maternal age-specific rates of numerical chromosome abnormalities with special reference to trisomy. Hum. Genet. 70 (1), 11-17 (1985).

5. Arck, P. C. et al. Early risk factors for miscarriage: a prospective cohort study in pregnant women. Reprod. Biomed. Online. 17 (1), 101-113 https://doi.org/10.1016/s1472-6483(10)60300-8 (2008).

6. Osmanağaoğlu, M. A. et al. The diagnostic value of beta-human chorionic gonadotropin, progesterone, CA125 in the prediction of abortions. J. Obstet. Gynaecol. 30 (3), 288-293 https://doi.org/10.3109/01443611003605286 (2010).

7. Lek, S. M. et al. Validation of serum progesterone $<35 \mathrm{nmol} / \mathrm{L}$ as a predictor of miscarriage among women with threatened miscarriage. $B M C$ Pregnancy Childbirth. 17, 78 https://doi.org/10.1186/s12884-017-1261-4 (2017).

8. Ku, C. W. et al. How can we better predict the risk of spontaneous miscarriage among women experiencing threatened miscarriage? Gynecol. Endocrinol. 31 (8), 1-5 https://doi.org/10.3109/09513590.2015.1031103 (2015).

9. Ku, C. W. et al. Gestational age-specific normative values and determinants of serum progesterone through the first trimester of pregnancy. Sci. Rep. 11 (1), 4161 https://doi.org/10.1038/s41598-021-83805-w (2021).

10. Warburton, D. Cytogenetics of reproductive wastage: from conception to birth in Medical Cytogenetics (ed. Hon Fong L., M.) 213-246 (CRC Press, 2000).

11. Gillen-Goldstein, J., Roque, H. \& Young, B. K. Steroidogenesis patterns in common trisomies. Journal of Perinatal Medicine. 30 (2), $132-136$ https://doi.org/10.1515/JPM.2002.016 (2002).

12. Kratzer, P. G., Golbus, M. S., Monroe, S. E., Finkelstein, D. E. \& Taylor, R. N. First-trimester aneuploidy screening using serum human chorionic gonadotropin (hCG), free ahCG, and progesterone. Prenat. Diagn. 11(10), 751 - 763. https://doi.org/10.1002/pd.1970111003 (1991).

13. Okada, H., Tsuzuki, T. \& Murata, H. Decidualization of the human endometrium. Reprod. Med. Biol. 17 (3), 220-227 https://doi.org/10.1002/rmb2.12088 (2018).

14. Coomarasamy, A. et al. A Randomized Trial of Progesterone in Women with Bleeding in Early Pregnancy. N. Engl. J. Med. 380, 1815-1824 (2019).

15. Chan, D. et al. Use of oral progestogen in women with threatened miscarriage in the first trimester: a randomized double-blind controlled trial. Human reproduction (Oxford, England). 36 (3), 587-595 https://doi.org/10.1093/humrep/deaa327 (2021).

16. Ku, C. W. et al. Serum progesterone distribution in normal pregnancies compared to pregnancies complicated by threatened miscarriage from 5 to 13 weeks gestation: a prospective cohort study. BMC Pregnancy Childbirth. 18 (1), 360 https://doi.org/10.1186/s12884-018-2002-z (2018).

17. Pylyp, L. Y. et al. Chromosomal abnormalities in products of conception of first-trimester miscarriages detected by conventional cytogenetic analysis: a review of 1000 cases. J Assist. Reprod. Genet. 35 (2), 265-271 https://doi.org/10.1007/s10815-017-1069-1 (2018).

18. Sahoo, T. et al. Comprehensive genetic analysis of pregnancy loss by chromosomal microarrays: outcomes, benefits, and challenges. Genet. Med. 19 (1), 83-89 https://doi.org/10.1038/gim.2016.69 (2017).

19. Bens, S. et al. Mosaic genome-wide maternal isodiploidy: an extreme form of imprinting disorder presenting as prenatal diagnostic challenge. Clin. Epigenet. 9, 111 https://doi.org/10.1186/s13148-017-0410-y (2017).

20. Li, T. C., Makris, M., Tomsu, M., Tuckerman, E. \& Laird, S. Recurrent miscarriage: aetiology, management and prognosis. Hum. Reprod. Update. 8 (5), 463481 https://doi.org/10.1093/humupd/8.5.463 (2002).

21. van den Berg, M. M. J., van Maarle, M. C. \& van Wely, M. \& M., Goddijn, M. Genetics of early miscarriage. Biochimica et Biophysica Acta - Molecular Basis of Disease. 1822 (12), 1951-1959 (2012).

22. Choi, T. Y., Lee, H. M., Park, W. K., Jeong, S. Y. \& Moon, H. S. Spontaneous abortion and recurrent miscarriage: A comparison of cytogenetic diagnosis in 250 cases. Obstet. Gynecol. Sci. 57 (6), 518-525 https://doi.org/10.5468/ogs.2014.57.6.518 (2014).

23. Hook, E. B. \& Warburton, D. Turner syndrome revisited: review of new data supports the hypothesis that all viable $45, \mathrm{X}$ cases are cryptic mosaics with a rescue cell line, implying an origin by mitotic loss. Hum. Genet. 133 (4), 417-424 https://doi.org/10.1007/s00439-014-1420-x (2014).

24. Grande, M. et al. The effect of maternal age on chromosomal anomaly rate and spectrum in recurrent miscarriage. Hum Reprod. 27 (10), $3109-3117$ https://doi.org/10.1093/humrep/des251 (2012).

25. Nikcevic, A. V., Tunkel, S. A., Kuczmierczyk, A. R. \& Nicolaides, K. H. Investigation of the cause of miscarriage and its influence on women's psychological distress. Br. J. Obstet. Gynaecol. 106 (8), 808-813 https://doi.org/10.1111/j.1471-0528.1999.tb08402.x (1999).

26. Knudsen, U. B., Hansen, V., Juul, S. \& Secher, N. J. Prognosis of a new pregnancy following previous spontaneous abortions. Eur. J. Obstet. Gynecol. Reprod. Biol. 39 (1), 31-36 https://doi.org/10.1016/0028-2243(91)90138-b (1991).

27. Nybo Andersen, A. M., Wohlfahrt, J., Christens, P., Olsen, J. \& Melbye, M. Maternal age and fetal loss: population based register linkage study. BMJ. 320 (7251), 1708-1712 https://doi.org/10.1136/bmj.320.7251.1708 (2000).

28. Cohain, J. S., Buxbaum, R. E. \& Mankuta, D. Spontaneous first trimester miscarriage rates per woman among parous women with 1 or more pregnancies of 24 weeks or more. BMC Pregnancy Childbirth. 17, 437 https://doi.org/10.1186/s12884-017-1620-1 (2017).

29. Munné, S. et al. Increased rate of aneuploid embryos in young women with previous aneuploid conceptions. Prenat. Diagn. 24 (8), 638-643 https://doi.org/10.1002/pd.957 (2004).

30. Warburton, D. et al. Trisomy recurrence: a reconsideration based on North American data. Am. J. Hum. Genet. 75 (3), 376-385 https://doi.org/10.1086/423331 (2004).

31. Bianco, K., Caughey, A. B., Shaffer, B. L., Davis, R. \& Norton, M. E. History of miscarriage and increased incidence of fetal aneuploidy in subsequent pregnancy. Obstet. Gynecol. 107 (5), 1098-1102 https://doi.org/10.1097/01.AOG.0000215560.86673.22 (2006). 
32. De Souza, E., Halliday, J., Chan, A., Bower, C. \& Morris, J. K. Recurrence risks for trisomies 13, 18, and 21. Am. J. Med. Genet. A. 149A (12), 2716-2722 https://doi.org/10.1002/ajmg.a.33099 (2009).

33. Royal College of Obstetricians and Gynaecologists. The Investigation and Treatment of Couples with Recurrent First Trimester and Second Trimester Miscarriage (RCOG, London, 2011). https://www.rcog.org.uk/globalassets/documents/guidelines/gtg_17.pdf

34. European Society of Human Reproduction and Embryology. Recurrent Pregnancy Loss - Guideline of the European Society of Human Reproduction and Embryology (ESHRE, Belgium, 2017). https://www.eshre.eu/Guidelines-and-Legal/Guidelines/Recurrent-pregnancy-loss

\section{Tables}

\begin{tabular}{|c|c|c|c|c|c|c|c|c|c|c|c|}
\hline \multirow[b]{2}{*}{ Case } & \multicolumn{8}{|c|}{ Demographics } & \multicolumn{3}{|c|}{ POC Genetics profile } \\
\hline & $\begin{array}{l}\text { Age } \\
\text { (years) }\end{array}$ & Race & $\begin{array}{l}\text { BMI } \\
\left(\mathrm{kg} / \mathrm{m}^{2}\right)\end{array}$ & $\begin{array}{l}\text { No. of } \\
\text { previous } \\
\text { miscarriages }\end{array}$ & $\begin{array}{l}\text { Gestation } \\
\text { age at } \\
\text { recruitment } \\
\text { (weeks) }\end{array}$ & $\begin{array}{l}\text { Gestation } \\
\text { age at } \\
\text { miscarriage } \\
\text { (weeks) }\end{array}$ & $\begin{array}{l}\text { Progesterone } \\
\text { level } \\
\text { (nmol/L) }\end{array}$ & $\begin{array}{l}\text { Progesterone } \\
\text { supplementation } \\
\text { given } \\
(\mathrm{Y} / \mathrm{N})\end{array}$ & $\begin{array}{l}\text { Aberrant } \\
\text { profile } \\
(\mathrm{Y} / \mathrm{N})\end{array}$ & $\begin{array}{l}\text { Detailed } \\
\text { profile }\end{array}$ & Genc \\
\hline 1 & 37 & Others & NA & 0 & 6.29 & 6.57 & 5.0 & Y & Y & Trisomy 16 & $X Y$ \\
\hline 2 & 35 & Malay & 33.6 & 0 & 5.86 & 5.86 & 9.0 & $\mathrm{Y}$ & $\mathrm{Y}$ & $\begin{array}{l}\text { Mosaic } \\
\text { genome } \\
\text { wide UPD } \\
\text { for all } \\
\text { autosomes }\end{array}$ & $\begin{array}{l}\text { Mosi } \\
\text { XX/X } \\
\text { profi }\end{array}$ \\
\hline 3 & 31 & Chinese & 19.0 & 0 & 5.28 & 5.43 & 10.0 & $\mathrm{Y}$ & $\mathrm{Y}$ & $\begin{array}{l}\text { Trisomy } 5 \\
\text { and } 7\end{array}$ & $X Y$ \\
\hline 4 & 33 & Others & 26.2 & 0 & 5.00 & 7.00 & 12.6 & Y & $\mathrm{Y}$ & $\begin{array}{l}\text { Mosaic } \\
\text { genome } \\
\text { wide UPD } \\
\text { for all } \\
\text { autosomes }\end{array}$ & $\begin{array}{l}\text { Mosi } \\
\text { XX/X } \\
\text { profi }\end{array}$ \\
\hline 5 & 32 & Malay & 33.2 & 0 & 9.00 & 9.14 & 16.2 & $\mathrm{Y}$ & Y & $\begin{array}{l}\text { Trisomy } 8 \\
\text { and } 20\end{array}$ & $X Y$ \\
\hline 6 & 32 & Chinese & 22.8 & 0 & 6.71 & 9.29 & 42.9 & $\mathrm{~N}$ & $\mathrm{~N}$ & $\begin{array}{l}\text { Normal } \\
\text { profile }\end{array}$ & $X Y$ \\
\hline 7 & 37 & Chinese & 20.7 & 0 & 6.28 & 8.14 & 53.9 & $\mathrm{~N}$ & $\mathrm{Y}$ & $\begin{array}{l}\text { Trisomy } 22 \\
\text { with } \\
\text { monosomy } \\
\text { X }\end{array}$ & $X Y$ \\
\hline 8 & 23 & Indian & 24.4 & 0 & 6.28 & 7.86 & 54.4 & $\mathrm{~N}$ & NA & $\begin{array}{l}\text { Indetermina } \\
\text { due to poor } \\
\text { quality }\end{array}$ & $\begin{array}{l}\text { result } \\
\text { NA }\end{array}$ \\
\hline 9 & 34 & Chinese & 21.8 & 0 & 5.00 & 9.29 & 61.2 & $\mathrm{~N}$ & $Y$ & $\begin{array}{l}\text { Monosomy } \\
\text { X }\end{array}$ & $X X$ \\
\hline
\end{tabular}

\section{Figures}




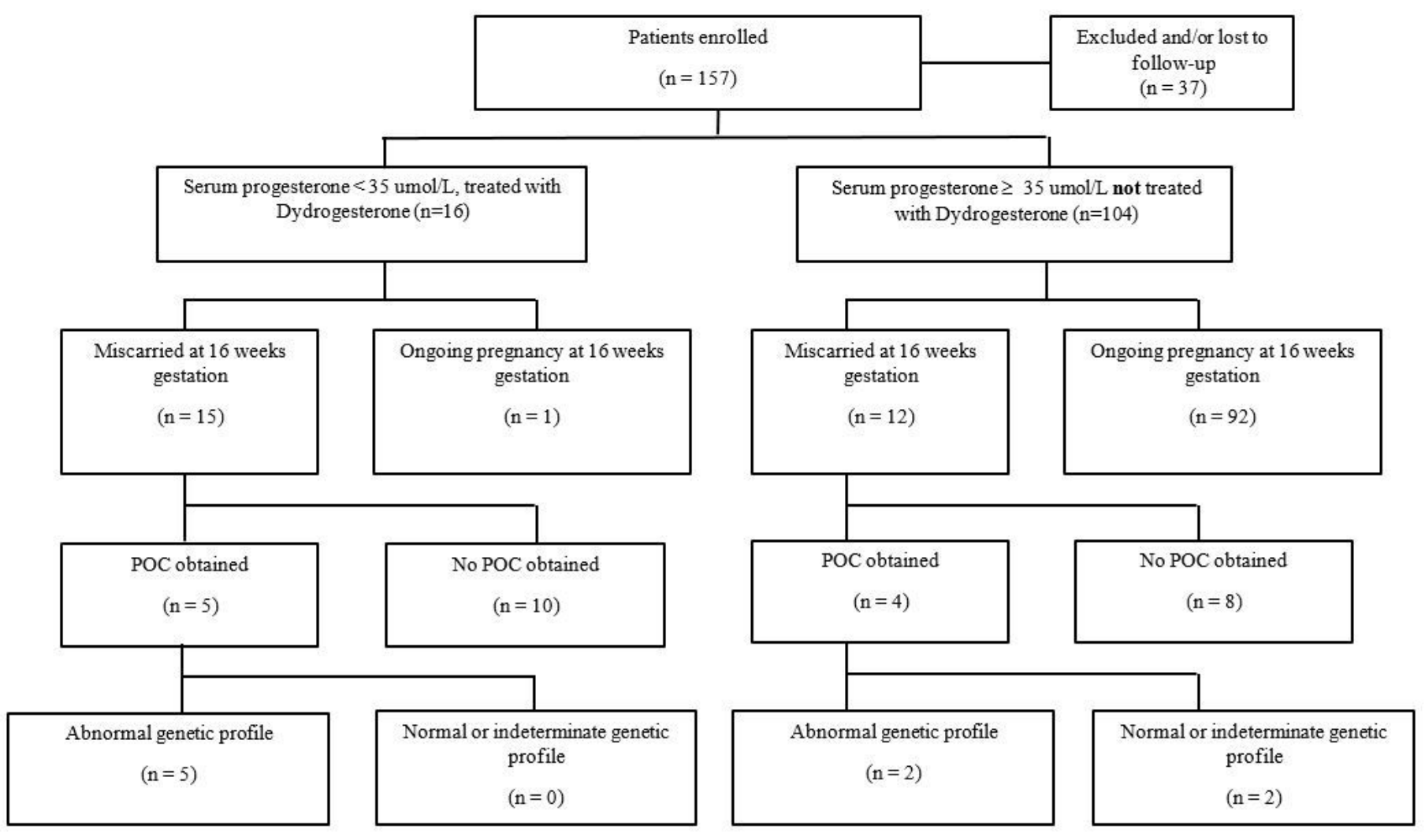

Figure 1

Study Recruitment Flowchart 